\title{
Co-Administration of Nonsteroidal Ant-Inflammtory Drugs and Gastropotective Drugs in Orthopaedic Out Patient Department of a University Hospital in Kashmir
}

\author{
Jawed Bhat,Tabasum Akbar, Faizan , Naser Mir
}

\begin{abstract}
Nonsteroidal ant-inflamatory drugs are commonly prescribed in out-paient orthopaedic department for acute inflammatory conditions like soft tissue injuries,sports injuries,trauma ;post surgery conditions or chronic inflammatory conditions like lumbago,rheumatoid arthritis and osteoarthritis.To avoid side effects of these NSAIDS ,common gastroprotecive drugs prescribed are proton pump inhibitors, H2 blockers, sucralfate, antacids and misoprostol.
\end{abstract}

Study Design: A cross-sectional,single centre drug utilization was conducted.Prescriptions were obtained from patients attending OPD.The prescription pattern of NSAIDS, gastroprotective drugs or co-administration were evaluated.

Results: A total of 1500 prescriptions were evaluated;in which 1439(95.9 percent) prescriptions contained nonsteroidal anti-inflammatory drugs with gastroprotective drugs.The most common gastroprotective agents combined with nonsteroidal antinflammatory drugs were PPI(proton pump inhibitors)[52.46percent] followed by $\mathrm{H} 2$ receptor antagonists [32.73], while antacids[14.73] were prescribed least.

\section{Introduction}

Non-stroidal anti-inflammatory drugs(NSAID) are commonly used drugs for years of management of pain and inflammation with good efficacy and represent most widely prescribed class of medications in the world and are used as over the counter drugs(OTC) [1].NSAIDS inhibit cycloxyenase(COX) enzymes which catalyse the metabolism of arachidonic acid into prostaglandis.COX is available in two isoforms i.e COX-1 and COX-2[ 2,3].The COX-1 enzyme is constitutive in nature involved in generating prostaglandins for physiological function like gastric protection,regulation of renal blood flow and platelet homeostasis. While COX-2 has been termed as an inducible enzymes involved in inflammation,colorectal cancer and neurodegenerative disorders [4].A new isoform COX-3 has been recently discovered,although its role is yet not clear [5].

Despite wide clinical use of classical NSAIDS as analgesics,anti-pyretics, and anti-inflammatory agents their gastro-intestinal toxicity(dyspepsia,peptic ulcers and gastrointestinal bleeds) is a major clinical limitation [6].Selective COX-2 inhibitors were developed with the aim of minimizing gastrointestinal toxicity[7].However,clinical and experimental data,as well as reviews suggest that the long term use of selective COX-2 inhibitors is associated with an increase in systolic blood pressure and cardiovascular morbidity and mortality due to myocardial infarction $[8,9]$.

Acid peptic diease is very common in kashmir and use of NSAIDs acts as a predisposing factor for ulcerative disease.Nearly $10-20 \%$ of the patients who are in use of NSAIDs develop asymptomatic peptic ulceration and ulcer -related complications in 1-2\% of the persons per year [10].This warrants a cautious use of NSAIDs in high risk individuals who include the elderly,those already receiving gastro-toxic agents and those with a history of gastro-intestinal diseases [11].So, the best alternative in such individuals would be the coadministration of NSAIDs with gastroprotective drugs.Misoprostol,an analog of prostaglandin E1, has been specifically approved for the prevention of NSAID-induced ulcers in high -risk patients [12,13].Proton pump inhibitors, $\mathrm{H} 2$ blockers have been used successfully to counter the side-effects of these anti-inflammatory drugs.

Our drug utilization was conducted to study the co-administration of non-steroidal anti-inflammatory drugs(NSAIDs) with gastroprotective drugs in postgraduate out patient unit of a university hospital.

\section{Material Methods}

The Study was done on 1500 patients in Skims Medical college Hospital affliated to Skims university.A written consent was taken from the patient for participation in the study.All patients using NSAIDs with or without gastroprotective agents ,between 16-70 years of age,irrespective of sex were studied.patients older than 70 years,lactating mothers,pregnant and mentally unfit were excluded . 


\section{Results}

In a one year period from April 2014 to march 2015, a total of 1500 patients were studied.The prescriptions were assessed only once.The demographic data is depicted in ,

Table 1: Demographic Data

\begin{tabular}{|lcc|}
\hline Patient profile & no of prescription & percentage \\
\hline Age in yrs & & 15.33 \\
\hline $17-30$ & 230 & 17.2 \\
\hline $31-40$ & 258 & 24.8 \\
\hline $41-50$ & 372 & 24.6 \\
\hline $51-60$ & 370 & 18.0 \\
\hline $61-70$ & 270 & \\
\hline SEX & & 52.53 \\
\hline Male & 788 & 47.46 \\
\hline Female & 712 & 20.0 \\
\hline Diagnosis & 300 & 13.5 \\
\hline Trauma & 203 & 6.7 \\
\hline Postoperative & 101 & 13.8 \\
\hline Sports Injuries & 208 & 18.0 \\
\hline $\begin{array}{l}\text { Cervical } \\
\text { spondylosis }\end{array}$ & 270 & 17.9 \\
\hline Low backache & 6.7 \\
\hline Osteoarthritis & 269 & 3.2 \\
\hline $\begin{array}{l}\text { Rheumatoid } \\
\text { arthritis }\end{array}$ & 101 & \\
\hline Others & 48 & \\
\hline
\end{tabular}

Among the 1500 prescriptions with oral NSAIDs, the number of prescriptions with gastroprotective agents were $1439(95.9 \%)$.

The gastroprotective agents prescribed were proton pump inhibitors,H2 Blockers and antacids.

Table 2: Shows different Gastroprotective Drugs

\begin{tabular}{|lcc|}
\hline Name of the & number of prescription & percentage \\
\hline $\begin{array}{l}\text { Gastroprotective } \\
\text { agents }\end{array}$ & [total 1439] & \\
\hline H2 Antagonists & 471 & 32.73 \\
\hline Famotidine & 302 & 38.8 \\
\hline Ranitidine & 476 & 61.1 \\
\hline Proton pump Inhibitors & 755 & 52.46 \\
\hline Omperazole & $12 \mathrm{o}$ & 24.0 \\
\hline Esomeprazole & 98 & 19.6 \\
\hline Pantoprazole & 158 & 31.6 \\
\hline Rabepraole & 102 & 20.4 \\
\hline Lansoprazole & 22 & 4.4 \\
\hline Antacid preparation & 212 & 14.73 \\
\hline
\end{tabular}

The drugs enlisted in table 2 have been used as gastroprotective agents.

The use of gastroprotective drugs along with the seven commonly used NSAIDs, either as single drug or fixed dose combinations(FDC), is shown in table 3.

Table 3: combination of NSAIDs and gastroprotective drugs

NSAIDs no of prescriptions co-prescription of GP

$$
\text { N\% PPI } \mathrm{H} 2 \text { antagonist Antacids }
$$

$\begin{array}{llllll}\text { Paracetamol } & 120 & 117(97.5) & 15 & 11 & 91\end{array}$

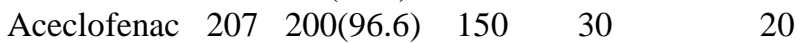

$\begin{array}{lllll}\text { Ibuprofen } & 283 & 280(98.9) & 88 & 160\end{array}$

$\begin{array}{llll}\text { Aceclofenac+thio300 290(96.6) } & 200 \quad 70 & 70\end{array}$

$\begin{array}{llllll}\text { Diclofenac } & 91 & 90(98.9) & 60 & 30 & 1\end{array}$

Diclof+PCM+chloroxzone101 100(99.) $1 \quad 0 \quad 0$

$\begin{array}{llllll}\text { Etoricoxib } & 57 & 50(87.7) & 30 & 18 & 2\end{array}$

$\begin{array}{llllll}\text { Etorcoxib+Thio } & 30 & 25(71.40) & 15 & 7 & 3\end{array}$

$\begin{array}{llllll}\text { Piroxicam } & 151 & 150(99.3) & 37 & 85 & 28\end{array}$

$\begin{array}{lllll}\text { Tramadol+PCM } 140 & 132(94.2) & 60 & 60 & 12\end{array}$

$\begin{array}{llllll}\text { Lornoxicam } & 20 & 5(25 .) & 0 & 2 & 3 \mathrm{~s}\end{array}$




\section{Discussion}

One has to be guarded when prescribing analgesics to patients in Vale of Kashmir in view of the fact that acid peptic disease is very common here.The use of selective COX-2inhibitors seems to have decreased after the the cardiac adverse effects which were observed with these drugs [8,9].Diclofenac+ $\mathrm{PCM}+$ Chlorzoxazone,Aceclofenac +Thiocolchicoside,Etoricoxib,Lornoxicam,Piroxicam,PCM+Tramadol were most commonly co-prescribed NSAIDs with a gastroprotective agent-100\%.Ibuprofen was the second most commonly used NSAID with a gastroprotective agent-97.92\%.PPIs produce more sustained acid suppression as compared to $\mathrm{H} 2$ antagonists and promote ulcer healing despite continued NSAIDS Therapy [14,15].But in the present series $\mathrm{H} 2$ antagonists were the most commonly used gastroprotective agents,followed by proton pump inhibitors.This is because $\mathrm{H} 2$ blockers are cheap.Antacids were used least , the reason being that these were less effective than PPIs and $\mathrm{H} 2$ antagonists.

Antacids are indicated only for symptomatic relief of pain and are associated with a number of drug interactions,thereby restricting their use[11].Misoprostol,the drug indicated for the prophylaxis of high risk individuals, were not used at all.This may be because of various reasons including the higher cost,frequent side effects and the need for multiple daily dose of Misoprostol.In any case,similar or even better efficacy is obtained by proton pump inhibitors in preventing and/or treating NSAID-inuced peptic ulcers[16,17].Sucralfate was not used as gastroprotective drug in our series.

The drugs Paracetamol(PCM),Diclofenac,Ranitidine and Omperazole were supplied in hospital free of cost.The limitation of this study was that after initial registration there was no follow-up and no ADR reporting.The strong point was larger number of the patients, easy accessibility.

\section{Funding: None}

\section{Conflicting Interest: None}

\section{References}

[1] Sharma T,Dutta S,Dhasmana DC.Prescribing pattern of NSAIDs in orthopaedic OPD of a tertiary care teaching hospital in Uttaranchal .JK Sci 2006;8:160-2

[2] Vane JR.Inhibition of prostaglandin synthesis as a mechanism of action for aspirin like drugs.Nat New Biol 1971;231:232-5

[3] Warner TD,Mitchell JA.Cycloxygenase:new forms,new inhibitors and lessons from the clinic.FASEB J 2004;18:790-804.

[4] Marnett LJ,Rowlinson SW,Goodwin DC,Kalgutkar AS,Lanzo CA.Arachidonic acid oxygenation by COX-1 and COX2.Mechanisms of catalysis and inhibition.J Biol Chem 1999;274:22903-6

[5] .Chandrasekharan NV,Dai H,Roos KC,et al.Cox-3,a cycloxygenase-1 variant inhibited by acetaminophen and other analgesic/antpyretic drugs:cloning,structure and expression.proc Natl Acad Sci USA 2002;99:13926-31

[6] Graumlich JF.Preventing gastrointestinal complications of NSAIDs:risk factors,recent advances,and latest strategies.Postgrad Med 2001;109:117-28

[7] Hawkey Cj.COX-2 inhibitors.Lancet 1999;353:307-14

[8] .Mukherjee D,Nissen SE,Topol EJ.Risk of cardiovascular events associated with selective COX-2 inhibitors.JAMA 2001;286:954-9

[9] jain s,Gupta M,Malhotra S,Pandhi P.Effect of Rofecoxib on antihypertensive effects of candesartan in experimental models of hypertension.Methods Find Exp Clin Pharmacol 2005;27:11-6

[10] Mcquaid KR.Drugs used in the treatment of Gastrointestinal Diseases.In:Katzung BG,editor.Basic and Clinical Pharmacology,10 ed.Mcgraw Hill;2007:1009-19

[11] Raghavendra B,Sanji N,Ullal SD,et al. Trends in prescribing gastroprotective Agents with Non Steroidal Anti-inflammatory Dugs in an Orthopaedic Outpatient unit of a Tertiary Care Hospital.J Clin Diagn Res 2009;3:1553-6

[12] Hopkinson N,Doherty M.NSAIDS-associated gastropathy-a role for misoprostol? Br J Rheumatol 1990;29:133-6

[13] Walt RP.Misoprostol for the treatment of peptic ulcer and antiinflamatory-drug induced gastroduodenal ulceration.N Engl J Med 1992:327:1575-80

[14] Gisbert JP,Gonzalez L,Calvet X,Roque M,Gabriel R,Pajares JM,Proton Pump inhibitors versus H2-antagonists: a meta-analysis of their efficacy in treating bleeding peptic ulcer.Alimen Pharmacol Ther 2001;15:917-26

[15] La Corte R,Caselli M,Castellino G,Bajocchi G,Trotta F.Prophylaxis and treatment of NSAID-induced gastroduodenal disorders Drug Saf 1999;20:527-43.

[16] Dupas JL,Grigy C,Curative and preventive treatment of NSAID-associated gastroduodenal ulcers.Gastroenterol Clin Biol 2004;28:c77-83.

[17] Lazzaroni M,Porro GB.Management of NSAID-induced gastrointestinal toxicity:focus on proton pump inhibitors.Drugs 2009;69:51-69. 